\title{
ANALISIS KOMUNIKASI KONSUMEN TERHADAP FIDUSIA LEASING KENDARAAN PADA STUDI KASUS DEBT. COLLECTOR DENGAN FIDUCIARY VEHICLE SYSTEM METHODS
}

\author{
Hefri Yodiansyah ${ }^{1}$, Nanik Yuzalmi ${ }^{2}$ \\ ${ }^{1}$ Dosen Jurusan Ilmu Komunikasi, Sekolah Tinggi Ilmu Sosial dan Ilmu Politik Persada Bunda, \\ ${ }^{2}$ Dosen Akademi Sekretari dan Manajemen Persada Bunda \\ Email: ${ }^{1}$ hefri.yordiansyah@gmail.com, ${ }^{2}$ n.yuzalmi@gmail.com
}

Diterima : 17 Juli 2018

Disetujui : 15 Agustus 2018

Diterbitkan : 31 Agustus 2018

\begin{abstract}
Abstrak
Debt. collector dengan Fiduciary Vehicle System Method dengan istilah FVSM. Dengan sistem analisis FVSM dengan metode pengendalian kendaraan fidukatif sebagai sistem pembayaran kendaraan pada sistem leasing, sebagai pola keseimbangan kepercayaan bisnis dan fungsi fidusia. Sehingga sistem metode pengendalian kendaraan fidukatif sebagai sistem pembayaran kendaraan fidukatif untuk jaminan sistem fidusia sebagai lingkup terapan sistem leasing bisnis kendaraan. Pelakuan sistem dengan metode pengendalian kendaraan fidukatif untuk jaminan mencegah konflik pada pola keseimbangan kendaraan fidukatif untuk mempelajari sistem itu lebih aman terkendali pada sistem fidusia yang dilakukan oleh masyarakat. Secara sistem analogy dengan metode pengendalian dan pengawasan kendaraan fidukatif untuk mengembalikan sistem kepercayaan bisnis pada pola sistem fidusia yang memberi kemudahan. Dengan sistem FVSM adalah proses kajian sistem komunikasi bisnis pada pola metode pengendalian kendaraan fidukatif untuk jaminan mencegah Konflikpada pola keseimbangan kendaraan fidukatif untuk mempelajarisistemitu lebih aman terkendali pada sistem pengamanan asset lingkungan bisnis.
\end{abstract}

Kata Kunci: Perencanaan Komunikasi, Analogy, Kepercayaan, FVSM.

\begin{abstract}
Debt. collector with Fiduciary Vehicle System Method with the term FVSM. With FVSM analysis system with fiducative vehicle control method as vehicle payment system in leasing system, as the pattern of business trust balance and fiduciary function. So the system of vehicle control method as fiducative vehicle payment system for fiduciary system guarantee as applied scope of vehicle business leasing system. The recognition of the system by the method of vehicle control fiducative for guarantees to prevent conflicts in the pattern of fiducative vehicle balance to study the system is more safely controlled on the fiduciary system conducted by the community. It analogy system with controlling method and supervision of vehicles fiducative to restore business trust system on pattern of fiduciary system which gives ease. With the FVSM system is a process of studying business communication systems on the pattern of vehicle control methods fiducative for guarantees to prevents conflicts in the pattern of vehicle fiducative balance to learn the system is more secure controlled on the security system asset business environment.
\end{abstract}

Keywords: Communication Planning, Analogy, Trust, FVSM.

\section{PENDAHULUAN}

Kemajuan teknologi dan informasi (technology and information literacy) pada perusahaan dealer leasing kendaraan kredit dengan mekanisme fidusia fiducative. Dengan Perubahan komunikasi massa, bisnis, dan tindakan regulasi industri fidusia pada unit kendaraan fiducative dengan perusahaan dealer leasing kendaraan kredit. Ini memerlukan 
mekanisme fidusia pada regulasi fidusia yang terapan sebagai komunikasi bisnis sebagai layanan etika bisnis dan tindakan kriminal kredit kendaraan fiducative oleh pihak-pihak fidusia pada kemasan berita Criminalists ini. Dengan kecanggihan teknologi dan media massa dalam memberikan informasi dan literasi pengetahuan (knowledge) kehadapan khalayak (pembaca) dengan sistem dan mekanisme berita sistem fidusia leasing kendaraan kreditfiducative pada studi kasus debt. collector.

Akses berita (Criminalists news) dengan mekanisme larangan leasing atau perusahaan pembiayaan untuk menarik secara paksa kendaraan fiducative dari nasabah yg menunggak kredit kendaraan fiducative. Siapakah debt collector? Nasabah kendaraan kredit dan segala jenis kredit kendaraan dan dengan ketentuan notaris yang pernah terlambat membayar cicilan, mungkin pernah ditagih debt collector. Merekalah yang menyelesaikan tagihan kredit yang belum dibayar.

Sumber berita (needs news source) Debt. Collector dengan pengetahuan (knowledge) mengenai Debt. Collector sebagai lingkup sistem fidusia pada proses kajian bidang bisnis kendaraan yang file asing dengan sistem fidusia. Dengan istilah disebutkan Debt. Collector atau dealer leasing kendaraan dalam langkah waktu yang telah ditentukan. Arti kata Debt. Collector adalah Saat ini semakin banyak nasabah kredit berurusan dengan debt. collector. Mereka ditelpon hingga didatangi rumahnya oleh debt collector. Tidak jarang nasabah kredit panik dan merasa ketakutan saat menghadapi tagihan debt. Collector.

Ketika Debt.Collector diminta oleh perusahaan dealer, jika pemilik kendaraan kredit tidak membayar utang dalam jangka waktu cukup lama. Sehingga utang kendaraan kredit itu masuk kategori macet. Selain menagih utang yang menumpuk, para debt. collector akan menagih jika pemilik kendaraan kredit tidak memberikan informasi atau kabar kapan akan membayar tagihan.

Namun sering terjadi, banyak pemilik kendaraan kredit merasa ketakutan saat ditagih oleh debt. collector. Akibatnya pemilik kendaraan kredit tidak mau menemui debt collector dan cenderung menghindar. Akhirnya, tidak tercapai penyelesaian atas utang kendaraan kredit. Jika sewaktu-sewaktu keuangan sedang terganggu sehingga tidak bisa melunasi utang kendaraan kredit lalu ditagih oleh debt. collector, sebaiknya tidak perlu panik dulu. Sebab sudah ada aturan yang memberikan perlindungan cukup jelas bagi para pemegang kendaraan kredit perusahaan dan Pemerintah keuangan, serta lembaga yang mengatur sistem pembayaran kendaraan dengan sistem fidusia ini.

Istilah Debt. Collector dalam sistem fidusia menurut asal katanya berasal dari bahasa Romawi fides yang berarti kepercayaan. Fidusia merupakan istilah yang sudah lama dikenal dalam bahasa Indonesia. Begitu pula istilah ini digunakan dalam Undang-undang Nomor 42 Tahun 1999 tentang Jaminan Fidusia. Dalam terminologi Belanda istilah ini sering disebut secara lengkap yaitu Fiduciare Eigendom Overdracht (F.E.O.) yaitu penyerahan hak milik secara kepercayaan. Sedangkan dalam istilah bahasa Inggris disebut Fiduciary Transfer of Ownership.

Definisi fidusia dengan fidusia adalah pengalihan hak kepemilikan sebuah benda dimana hak kepemilikannya masih dalam kekuasaan pemilik benda tersebut. Dengan mekanisme leasing kendaraan pada perusahaan dealer dengan istilah Debt. Collector pada metode fidusia sebagai lingkup metode fidusia pada Debt. Collector. Dengan metode Debt. Collector ini dalam perusahaan bisnispembeli yang mengalami permasalahan yang akan disidangkandan pengadilan akan mengeluarkan surat keputusan untuk menyita kendaraan dan kendaraan akan dilelang oleh pengadilan dan uang hasil penjualan kendaraan melalui lelang tersebut akan digunakan untuk melanjutkan membayar utang kredit kepada perusahaan dealer leasing, lalu uang sisanya akan diberikan dengan sistem fidusia ini. 
Contohnya, ketika melakukantransmisi dengan kredit kendaraan dengan menggunakan mekanisme fidusia yang diatur dalam mempermudah dan mengatasi kredit kendaraan pada sebuah perusahaan dealer. Maka pihak pemberi kredit akan membeli ke perusahaan dealer dengan mekanisme fidusia ini. Maka, kendaraan tersebut adalah milik pemberi kredit dan hak miliknya dialihkan kepada pembeli. Selama membeli yang belum dapat melunasi kredit maka kendaraan tersebut milik pemberi kredit pada perusahaan dealer itu.

Peraturan fidusia dengan sumber tentang mekanisme sistem Fidusia, yaitu:

a) Bank Indonesia dalam Surat Edaran BI No. 15/40/DKMP tanggal 23 September 2013

b) Peraturan Menteri Keuangan (PMK) No.130/PMK.010/2012 tentang pendaftaran fidusia bagi perusahaan pembiayaan yang dikeluarkan tanggal 7 Oktober 2012.

c) Menurut Undang-Undang No 42 Tahun 1999, dengan fidusia adalah suatu proses mengalihkan hak milik atas suatu benda dengan dasar kepercayaan, tapi benda tersebut masih dalam penguasaan pihak yang mengalihkan.

Pada sistem perjanjian fidusia ini melindungi aset konsumen, leasing tidak bisa serta merta menarik kendaraan yang gagal bayar karena dengan perjanjian fidusia, alur yg seharusnya terjadi adalah pihak leasing melaporkan ke pengadilan. Proses fidusia sebagai wacana dengan metode sistem transmisi fidusia pada pihak leasing wajib mendaftarkan setiap transaksi kredit didepan notaris atas perjanjian fedusia ini.

Leasing Kendaraan pada Studi Kasus Debt. Collector dengan mekanisme sistem Fidusia sebagai lingkup metode fidusia pada Debt. Collector. Dalam kasus pembeli akan disidangkan dan pengadilan akan mengeluarkan surat keputusan untuk menyita kendaraan pembeli dan kendaraan pembeli akan dilelang oleh pengadilan dan uang hasil penjualan kendaraan melalui lelang tersebut akan digunakan utk membayar utang kredit pembeli ke perusahaan leasing, lalu uang sisanya akan diberikan kepada pembeli. Karena jika mereka membawa sepucuk surat fidusia (yang ternyata adalah palsu) silakan anda bawa ke hukum, pihak leasing akan didenda minimal Rp 1,5 milyar. Tindakan leasing melalui Debt Collector atau istilah lainnnya "mata elang" yang mengambil secara paksa kendaraan dirumah, merupakan tindak pidana Pencurian. Dengan pelakuan demikian pengambilan dilakukan di jalan, merupakan tindak pidana Perampasan. Sehingga sistem fidusia bisa dijerat Pasal 368, Pasal 365 KUHP Ayat 2, 3 dan 4 junto undang-undang yang berlaku.

Analisis komunikasi budaya dengan kriteria individual pada kepemilikan kendaraan kredit dengan mekanisme leasing sangat ideal. Ketika individual pada kepemilikan kendaraan kredit dengan mekanisme leasing sangat ideal bagi konsumen. Ketika melakukan pengambilan kendaraan terlebih dahulu mengetahui pola penghasilan konsumen itu sebagai etika bisnis dalam memenuhi persyaratan leasing kendaraan pada perusahaan dealer tertentu. Pola regulasi industri dan sistem fidusia itu untuk mengikuti mekanisme sistem leasing secara kredit kendaraan menggunakan metode kredit leasing kendaraan pada perusahaan dealer. Dengan mentaati persyaratan dengan prosedur atau mekanisme leasing agent pada perusahaan dealer itu dengan memanfaatkan pihak ketiga dalam mengatasi pembayaran kredit leasing kendaraan tersebut.

Perusahaan dan agent toko dealer leasing dengan pembeli kendaraan sebagai layanan sistem fidusia pada pola mekanisme sistem fidusia ini bisa menjadi referensi dalam mempelajari usaha kendaraan melalui proses kredit leasing kendaraan fiducative. Dengan pola keseteruan kredit leasing agen pada perusahaan dealer dengan sistem fidusia dapat memprofesionalkan sistem kredit di Indonesia. Pihak-pihak leasing dengan mekanisme sistem fidusia sebagai layanan bisnis pada tahap proses kredit leasing kendaraan. Perubahan 
perilaku kognitive sosial pada pihak-pihak dalam mekanisme sistem fidusia yang melakukan pengambilan leasing kendaraan tersebut.

Komunikasi bisnis pada permohonan kredit leasing kendaraan pada perusahaan dealer dengan pihak ketiga dapat menghindari pola keseteruan kredit di Indonesia. Konteks agent leasing kendaraan kredit pada perusahaan dealer dalam pola bisnis kendaraan dengan sistem fidusia. Karakteristik mekanisme fidusia yang diterapkan dapat memfilter atau seleksi permasalahan leasing perusahaan dealer pada masa depan. Kerangka kredit leasing kendaraan pada agentdealer kendaraan leasing dengan ketentuan teknis pihak ketiga pada proses kredit kendaraan.

\section{METODE PENELITIAN}

\section{Metode Penelitian}

Metode deskriptif lain yang sering digunakan dalam pendidikan adalah studi korelasi. Studi ini mempelajari hubungan dua variabel atau lebih, yakni sejauh mana variasi dalam satu variable berhubungan dengan variasi dalam variabel lain. Derajat hubungan variablevariabel dinyatakan dalam satu indeks yang dinamakan koefisien korelasi. Koefisien korelasi dapat digunakan untuk menguji hipotesis tentang hubungan antar variabel atau untuk menyatakan besar-kecilnya hubungan antara kedua variabel atau lebih variabel penelitian.

Studi korelasi bertujuan menguji hipotesis, dilakukan dengan cara mengukur sejumlah variabel dan menghitung koefisien korelasi antara variabel-variabel tersebut, agar dapat ditentukan variabel-variabel mana yang berkorelasi. Misalnya peneliti ingin mengetahui variabel-variabel mana yang sekiranya berhubungan dengan analisis data penelitian.

Semua variabel yang ada kaitannya (misal latar belakang pendidikan, supervisi akademik, dan lain-lain) diukur, lalu dihitung koefisien korelasinya untuk mengetahui variabel mana yang paling kuat hubungannya dengan analisis deskripsi pada sistem komunikasi konsumen.

\section{Waktu dan Tempat Penelitian}

1) Waktu Penelitian

Pada waktu penelitian yang telah ditentukan pada jadwal penelitian sesuai dengan tujuan penelitian dua bulan Februari s.d Juli Tahun 2018.

2) Tempat Penelitian

Penelitian ini dilaksanakan pada lokasi penelitian yang telah ditentukan sesuai dengan tujuan penelitian ini pada Agent Dealer Leasing (ADL) yang berada di Kota Pekanbaru.

\section{Populasi Sampel, dan Teknik Pengambilan Sampel}

Populasi sampel penelitian dengan kualifikasi dengan kriteria koresponden yang berada di perusahaan dan agenttoko dialerkendaraan sebagai sampel sebanyak 100 orang dengan pengumpulan sampel penelitian pada metode ADL sistem.

Dengan pengumpulan sampel penelitian ini pada teknik pengambilan sampel penelitian sesuai tujuan penelitian pada kriteria sampel penelitian. Dengan metode pengumpulan sampel penelitian dapat dilakukan penarikan sampel yang akan diuji dalam analisis data penelitian.

\section{Variabeldan Operasional Variabel Penelitian}

1. Variabel Penelitian :

1) KomunikasiKonsumen 
Komunikasi konsumen bisnis dalam membeli kendaraan leasing dengan sistem pembayaran kendaraan fiducative sebagai lingkup terapan komunikasi bisnis pada kategori sistem fidusia dengan jaminan kontrak kerjasama dengan akte notaris yang telah disepakati pada agent dan pemilik kendaraan dengan sungsi maupun cara sistem leasing kredit maupun kontan pada pelunasan asset kendaraan fiducative.

2) Sistem Konsumen

Kebutuhan konsumen dengan jaminan kontrak kerjasama dengan akte notaris yang telah disepakati pada agent dan pemilik kendaraan dengan sungsi maupun cara sistem leasing kredit maupun kontan pada pelunasan asset kendaraan fiducative. Dengan mekanisme pengalihan kendaraan leasing yang mengalami peralihan konflik peradilan hukum yang berlaku.

3) Definisi Fidusia

Sistem fidusia sebagai sistem dengan proses aturan dan mekanisme fidusia sistem pada asset kendaraan fiducative yang ingin dijual dengan ketentuan-ketentuan hukum yang ada dikontrak yang telah disepakati bersama (agent maupun pemilik) jika mengalami peralihan konfik dapat diambil secara peradilan hukum yang berlaku.

4) Leasing Kendaraan (Perusahaan dan Agent)

Leasing kendaraan adalah salah satu sistem fidusia pada sistem pembayaran kendaraan leasing dealer (agent) yang mengatasi konflik sebagai orang yang diberi wewenang menjalankan proses pembayaran leasing kendaraan fiducative. Sebagai sistem pembayaran kendaraan leasing dealer (fiducative agent) yang dapat mengatasi proses masalah kebutuhan kendaraan, seperti :

a. Sistem kontan

b. Sistem kredit

5) Debt. Collector

Sistem komunikasi bisnis pada sistem pembayaran kendaraan leasing dealer yang mengatasi konflik sebagai orang yang diberi wewenang menjalankan proses pembayaran leasing kendaraan fiducative yang masih mengalami masalah motif atau modus pembayaran kendaraan yang tidak tepat waktunya sebagai pihak eksekutor penarikan kendaraan itu dengan jaminan kesimbangan sistem pembayaran kendaraan fiducative sebagai lingkup terapan komunikasi bisnis.

2. Operasional Variabel Penelitian:

Tabel 1. Operasional Variabel Penelitian

\begin{tabular}{|c|l|l|l|}
\hline No. & Operasional Variabel & \multicolumn{1}{|c|}{ Perubahan Dimensi } & \multicolumn{1}{c|}{ Indikator } \\
\hline 1 & Komunikasi Konsumen & $\begin{array}{l}\text { Proses promosi dengan sistem } \\
\text { fidusia sebagai lingkup terapan } \\
\text { fidusia pada sistem } \\
\text { keseimbangan kendaraan } \\
\text { fiducative }\end{array}$ & $\begin{array}{l}\text { Komunikasi } \\
\text { konsumen bisnis }\end{array}$ \\
\hline 2 & Sistem Konsumen & $\begin{array}{l}\text { Sistem konsumen pada leasing } \\
\text { kendaraan fiducative untuk } \\
\text { jaminan fidusia sebagai sistem } \\
\text { fidusia }\end{array}$ & $\begin{array}{l}\text { Kebutuhan } \\
\text { Konsumen }\end{array}$ \\
\hline 3 & Definisi Fidusia & $\begin{array}{l}\text { Suatu proses rencana } \\
\text { operasional dalam mewujudkan } \\
\text { sistem fidusia sebagai sistem } \\
\text { pembayaran kendaraan }\end{array}$ & Sistem Fidusia \\
\hline
\end{tabular}




\begin{tabular}{|c|l|l|l|}
\hline & & $\begin{array}{l}\text { fiducative sebagai lingkup } \\
\text { terapan komunikasi bisnis }\end{array}$ & \\
\hline 4 & Leasing Kendaraan & $\begin{array}{l}\text { Agents support supplier pada } \\
\text { sistem fidusia yang berlaku } \\
\text { sesuai sistem pembayaran } \\
\text { kendaraan fiducative. }\end{array}$ & $\begin{array}{l}\text { Sistem kontan } \\
\text { Sistem Kredit }\end{array}$ \\
\hline 5 & Debt. Collector & $\begin{array}{l}\text { Pihak yang mampu } \\
\text { mengentaskan konflik pada } \\
\text { sistem fidusia sebagai lingkup } \\
\text { terapan komunikasi bisnis }\end{array}$ & $\begin{array}{l}\text { Sistem Komunikasi } \\
\text { bisnis pada sistem } \\
\text { pembayaran } \\
\text { kendaraan }\end{array}$ \\
\hline
\end{tabular}

Sumber : Hasil dan Pembahasan Penelitian dengan Olahan Data, 2018.

\section{Teknik Pengumpulan Data}

1) Teknik Pengambilan Data Primer

Sebagai lingkup kajian pengambilan pada analisis data sebagai uji dengan metode pengumpulan sampel pada teknik pengambilan data primer.

2) Teknik Pengambilan Data Sekunder

Pada proses pengambilan data sebagai lingkup kajian tambahan dengan uji metode pengumpulan sampel penelitian sebagai teknik pengambilan data sekunder.

\section{Teknik Analisis Data}

Teknik analisis data dengan upaya yang dilakukan dengan jalan bekerja dengan analisis data, mengorganisasikan data, memilah-milahnya menjadi satuan yang dapat dikelola, mensintesiskanya, mencari dan menemukan pola, menemukan apa yang penting dan apa yang dipelajari, dan memetuskan apa yang dapat diceritakan kepada orang lain dengan rekapitulasi data pada analisis data sebagai proses perjalanan sebagai berikut :

1) Mencatat yang menghasilkan catatan lapangan, dengan hal itu diberi kode agar sumber datanya tetap dapat ditelusuri,

2) Mengumpulkan, memilah-milah, mengklasifikasikan, mensintesiskan, membuat ikstisar, dan membuat indeksnya.

3) Berpikir, dengan jalan membuat agar kategori data itu mempunyai makna, mencari dan menentukan pola dan hubungan-hubungan, dan membuat temuan-temuan umum. Selajutnya analisis dengan menggunakan sistem Fiduciary Vehicle System Methods (FVSM) pada tahapan analisis data kualifikasi pada sistem FVSM, adalah sebagai berikut :

1) Membaca/mempelajari data, menandai kata-kata kunci dan gagasan yang ada dalam data.

2) Mempelajari kata-kata kunci itu, berupaya menemukan tema-tema yang berasal dari data.

3) Menuliskan 'model' yang ditemukan.

4) Koding yang telah dilakukan pada analisis data dengan proses mengelompokkan data.

Koding data adalah proses mengatur urutan data, mengorganisasikannya ke dalam suatu pola, kategori, dan satuan urutan dasar.

Dengan Fiduciary Vehicle System Methods (FVSM) mendefinisikan analisis data sebagai proses yang merinci usaha secara formal untuk menemukan tema dan merumuskan hipotesis kerja (ide) pada sistem ADL ini, seperti yang disarankan oleh data kualifikasi dan sebagai usaha untuk memberikan bantuan pada tujuan penelitian dan hipotesis framework pada penelitian ini. 


\section{HASIL DAN PEMBAHASAN PENELITIAN}

Dengan metode pengumpulan data dari informasi responden pada sampel penelitian ini sebanyak 100 orang yang memberikanalasan sistem kendaraan leasing fiducative dengan perencanaan komunikasi dalam mempelajari fungsi dan tugas dengan sistem fidusia, sebagai berikut:

Tabel2. Data Moral Reasons for Protecting Personal Pada Kebijakan Komunikasi

\begin{tabular}{|l|c|}
\hline \multicolumn{1}{|c|}{ Moral Reasons For Protection Personal Pada Kebijakan Komunikasi } & $\begin{array}{c}\text { Presentasi } \\
(\%)\end{array}$ \\
\hline Sikap kewajaran pendidikan & $30 \%$ \\
\hline Sikap kewajaran analogy & $20 \%$ \\
\hline Sikap kewajaran sistem keseimbangan konflik & $50 \%$ \\
\hline Sikap kewajaran sistem kepercayaan bisnis & $20 \%$ \\
\hline \multicolumn{1}{|c|}{ Jumlah } & $100 \%$ \\
\hline
\end{tabular}

Sumber : Hasil dan Pembahasan Penelitian dengan Olahan Data, 2018.

Tabel3.Sistem Kerjasama (Cooperation System) Pada Regulasi Sumber

\begin{tabular}{|l|c|}
\hline \multicolumn{1}{|c|}{ Sistem Kerjasama (Cooperation System) Pada Regulasi Sumber } & $\begin{array}{c}\text { Presentasi } \\
(\%)\end{array}$ \\
\hline $\begin{array}{l}\text { Sistem dengan pola komunikasi bisnis pada sistem masyarakat pemilik } \\
\text { kendaraan leasing }\end{array}$ & $30 \%$ \\
\hline $\begin{array}{l}\text { Sistem fidusia dengan alur konteks pembayaran sistem keseimbangan } \\
\text { pada pola fidusia }\end{array}$ & $15 \%$ \\
\hline Lingkup terapan konfliks padaevaluasi kinerja dan perilaku kerja & $25 \%$ \\
\hline $\begin{array}{l}\text { Proses evaluasi aturan perusahaan dan pemerintah dengan proses } \\
\text { kendaraan leasing }\end{array}$ & $10 \%$ \\
\hline $\begin{array}{l}\text { Metode tindak tutur dan administrasi pengawasan dan pengendalian } \\
\text { kendaraan fiducative }\end{array}$ & $20 \%$ \\
\hline \multicolumn{1}{|c|}{ Jumlah } & $100 \%$ \\
\hline
\end{tabular}

Sumber : Hasil dan Pembahasan Penelitian dengan Olahan Data, 2018.

Tabel4. Sistem Promosi dan Komunikasi (Promotion and Communication System)

\begin{tabular}{|l|c|}
\hline Sistem Promosi dan Komunikasi (Promotion and Communication System) & $\begin{array}{c}\text { Presentasi } \\
(\%)\end{array}$ \\
\hline $\begin{array}{l}\text { Fungsi dan cara mengatasi pengawasan dan pengendalian kendaraan } \\
\text { fiducative untuk jaminan mencegah }\end{array}$ & $25 \%$ \\
\hline $\begin{array}{l}\text { Sumber dan aksis komunikasi dalam tindak tutur dan aksi pada kebijakan } \\
\text { pengawasan dan pengendalian kendaraan fiducative untuk jaminan } \\
\text { mencegah }\end{array}$ & $25 \%$ \\
\hline $\begin{array}{l}\text { Kepastian hukum dalam penyelesaian perkara belum tegas diatur pada } \\
\text { pola hukum }\end{array}$ & $15 \%$ \\
\hline Hak pemilik kendaraan fiducative sebagai sistem fidusia & $15 \%$ \\
\hline Metode sistem komunikasi bisnis pada sistem pembayaran kendaraan & $20 \%$ \\
\hline \multicolumn{1}{|c|}{ Jumlah } & $100 \%$ \\
\hline
\end{tabular}

Sumber: Hasil dan Pembahasan Penelitian dengan Olahan Data, 2018. 
Pada implementasi dan penyelenggaraanpengawasan dan pengendalian pembayaran kendaraan fiducative untuk jaminan keseimbangan mengalihkan konflik leasing kendaraan, dengan pola sistem fiducative, sebagai berikut:

\section{Sistem Fidusia}

Definisi fidusia merupakan sistem pengalihan hak kepemilikan sebuah benda dimana hak kepemilikannya masih dalam kekuasaan pemilik benda tersebut. Dengan mekanisme leasing kendaraan pada perusahaan dealer dengan istilah Debt. Collector pada metode fidusia sebagai lingkup metode fidusia pada Debt. Collector. Dengan metode Debt. Collector ini dalam perusahaan bisnispembeli yang mengalami permasalahan yang dengan disidangkan dan pengadilan dengan mengeluarkan surat keputusan untuk menyita kendaraan dan kendaraan dengan dilelang oleh pengadilan dan uang hasil penjualan kendaraan melalui lelang itu dengandigunakan untuk melanjutkan dengan membayar utang kredit kepada perusahaan atau toko dealer kendaraan leasing, lalu uang sisanya akan diberikan dengan sistem fidusia ini (Fatma Paparang, Fakultas Hukum, \& Manado, 2014; Lindrawati \& Surabaya, 2009).

Contohnya, ketika melakukan transmisi dengan kredit kendaraan leasing pada menggunakan dengan mekanisme fidusia yang diatur sebagai mempermudah dan mengatasi beban kredit kendaraan pada sebuah perusahaan dealer kendaraan. Maka pihak pemberi kredit dapat membeli ke perusahaan dealer dengan mekanisme fidusia ini. Maka, kendaraan tersebut adalah milik pemberi kredit dan hak miliknya dialihkan kepada pembeli(Fatma Paparang et al., 2014). Selama membeli yang belum dapat melunasi kredit maka kendaraan tersebut pada milik pemberi kredit dengan perusahaan dealer kendaraan itu. Pada sistem fidusia pada alur efektif pengalaman pada konsumen bisnis dengan Fiduciary Vehicle System Methods (FVSM), seperti:

1) Sikap kewajaran Pendidikan

Pelakuan pada proses sistem fidusia sebagai sistem pembayaran kendaraan fiducative untuk jaminan fidusia menyelesaikan konflik kendaraan fiducative. Dengan prosedur pemberian kredit kewirausahaan. Data kulifikasi dengan prosedur pemberian kredit telah dilaksanakan dengan baik mulai dari pengajuan permintaan kredit, penyelidikan berkas jaminan, melakukan survey, mempelajari berkas-berkas kredit, sampai dengan pencairan kredit (Hayatdian, 2013). Selain itu pihak pegadaian telah melibatkan beberapa bagian antara lain: (1) Pimpinan cabang, (2) Perusahaan dan Agent Toko Kendaraan Leasing, (3) Notaris dan Debt. Collector, (4) Hukum Pengadilan, (5) Kasir pada alur leasing.

2) Sikap Kewajaran Pengetahuan

Sistem pengendalian kendaraan fiducative sebagai sistem fidusia yang dapat dihindarkan dengan sistem konflik pada sistem pembayaran kendaraan fiducative. Sehingga kepercayaan adalah perasaan percaya yang dirasakan konsumen tentang fidusia yang melindungi privasi konsumen, transaksi keamanan, layanan yang baik, juga kesesuaian barang. Sedangkan untuk mengukur kepercayaan yang melindungi privasi, dengan layanan baik, sesuai kesesuaian barang yang dijual dengan barang yang dipesan/dibeli (Anas, 2018; Sholihath, 2016; Stem, Margoluis, Salafsky, \& Brown, 2005), seperti : (1) Consumer Attitudes, (2) Price Fairness, (3) Trust, (4) Intentions of Consumers, (5) Online Agents(Sudapet, Sukoco, \& Setiawan, 2018).

3) Sikap Kewajaran Analogy

Kesadaran keseimbangan kendaraan fiducative sebagai sistem fidusia yang dapat diakses dengan sistem aksis pembayaran kendaraan fiducative untuk jaminan fidusia menyelesaikan pembayaran kendaraan sebagai sistem fidusia leasing ideal (Karianga, 2017). 
Kepercayaan terhadap sistem informasi yang baru mencerminkan sikap individu pemakai tentang keyakinan bahwa sistem yang baru ini memang lebih baik dengan sistem sebelumnya. Dengan kepercayaan ini bisa muncul karena kecepatan proses sistem yang baru dalam membatu pekerjaan, dan rasa keadilan dalam penerapan sistem baru ini bisa menilai kinerja individu dengan lebih baik (Yos, 2009).

4) Sikap Kewajaran Sistem Kepercayaan Bisnis

Kendalian dan pengendalian kendaraan fiducative sebagai sistem fidusia yang akan memberikan perlakuan sistem fidusia sebagai lingkup terapan fidusia menyelesaikan konflik (Anas, 2018).

\section{Mekanisme Fidusia}

Peraturan fidusia (law) dengan sumber tentang mekanisme sistem fidusia, yaitu:

1) Bank Indonesia dalam Surat Edaran BI No. 15/40/DKMP, tanggal 23 September 2013

2) Peraturan Menteri Keuangan (PMK) No.130/PMK.010/2012, tentang pendaftaran Fidusia bagi perusahaan pembiayaan yang dikeluarkan tanggal 7 Oktober 2012.

3) Menurut Undang-Undang No 42 Tahun 1999, fidusia adalah suatu proses mengalihkan hak milik atas suatu benda dengan dasar kepercayaan, tapi benda tersebut masih dalam penguasaan pihak yang mengalihkan.

Tabel 5. Mekanisme Sistem Fidusia Pada Konsumen Terhadap Komunikasi Bisnis

\begin{tabular}{|c|c|c|c|c|}
\hline No. & Mekanisme & $\begin{array}{c}\text { Analisis } \\
\text { Konsumen }\end{array}$ & $\begin{array}{c}\text { Data } \\
\text { Kualifikasi }\end{array}$ & $\begin{array}{c}\text { Komunikasi } \\
\text { Bisnis }\end{array}$ \\
\hline 1 & $\begin{array}{l}\text { Komunikasi konsumen } \\
\text { bisnis }\end{array}$ & $\begin{array}{l}\text { Hak milik } \\
\text { Kepercayaan } \\
\text { Penguasaan } \\
\text { pihak yang } \\
\text { mengalihkan }\end{array}$ & $\begin{array}{l}\text { Privacy } \\
\text { Consumer } \\
\text { System }(1)\end{array}$ & $\begin{array}{l}\text { Internal dan } \\
\text { Eksternal } \\
\text { system }\end{array}$ \\
\hline 2 & Kebutuhan Konsumen & $\begin{array}{l}\text { Sistem } \\
\text { memotivasi }\end{array}$ & $\begin{array}{l}\text { Communication } \\
\text { Analysis (2) }\end{array}$ & $\begin{array}{l}\text { Analisis } \\
\text { khalayak }\end{array}$ \\
\hline 3 & Sistem Fidusia & Peraturan sistem & $\begin{array}{l}\text { Privacy } \\
\text { Policy (3) }\end{array}$ & $\begin{array}{l}\text { Agenda } \\
\text { Society }\end{array}$ \\
\hline 4 & $\begin{array}{l}\text { Sistem Kontan } \\
\text { Sistem Kredit }\end{array}$ & Kontrak bisnis & $\begin{array}{l}\text { Cooperation } \\
\text { System (4) }\end{array}$ & Line System \\
\hline 5 & $\begin{array}{l}\text { Sistem komunikasi bisnis } \\
\text { pada sistem pembayaran } \\
\text { kendaraan }\end{array}$ & $\begin{array}{l}\text { Sistem promosi } \\
\text { dan Komunikasi }\end{array}$ & $\begin{array}{l}\text { Promotion and } \\
\text { Communication } \\
\text { System (5) }\end{array}$ & $\begin{array}{l}\text { Marketing } \\
\text { Komunikasi }\end{array}$ \\
\hline
\end{tabular}

Sumber: Peraturan Sistem Fidusia, 2018

Dengan konteks definisi fidusia pada metode pengawasan dan pengendalian kendaraan fiducative untuk jaminan mencegah konflik dengan pola keseimbangan kendaraan fidukatif. Dengan istilah methods of controlling vehicle fiducative for guarantees to prevent conflict on the pattern of vehicle fiducative balances (Fatma Paparang et al., 2014; Karianga, 2017). Sehingga metode data kualifikasi dengan sistem fidusia menyelesaikan konflik pembayaran kendaraan fidukatif, sebagai berikut:

1) Sistem Privasi Konsumer (Privacy ConsumerSystem)

a) Privasi Kondisional vs. Privasi Informasional (Constitutional vs. informational privacy). 
- Kondisional Privasi

Fungsi dan cara mengatasi pengawasan dan pengendalian kendaraan fiducative untuk jaminan mencegah konflik dengan pola keseimbangan kendaraan fiducative.

- Informasional Privasi

Sumber dan aksis komunikasi dalam tindak tutur dan aksi pada kebijakan pengawasan dan pengendalian kendaraan fidukatif untuk jaminan mencegah konflik dengan pola keseimbangan kendaraan fiducative yang telah ditentukan dengan aktual dan faktual dengan akal sehat.

b) Akun memberi nilai privasi (accounts of the value of privacy).

Akun menggunakan nilai privasi pada lingkup konflik dengan memberikan metode tindak tutur dan administrasi pengawasan dan pengendalian kendaraan fiducative untuk jaminan mencegah konflik dengan pola keseimbangan kendaraan fiducative (Lindrawati \& Surabaya, 2009).

c) Personal Data (Sholihath, 2016).

Skema 1. Akun Nilai Keseimbangan Privasi Kendaraan Pemilik

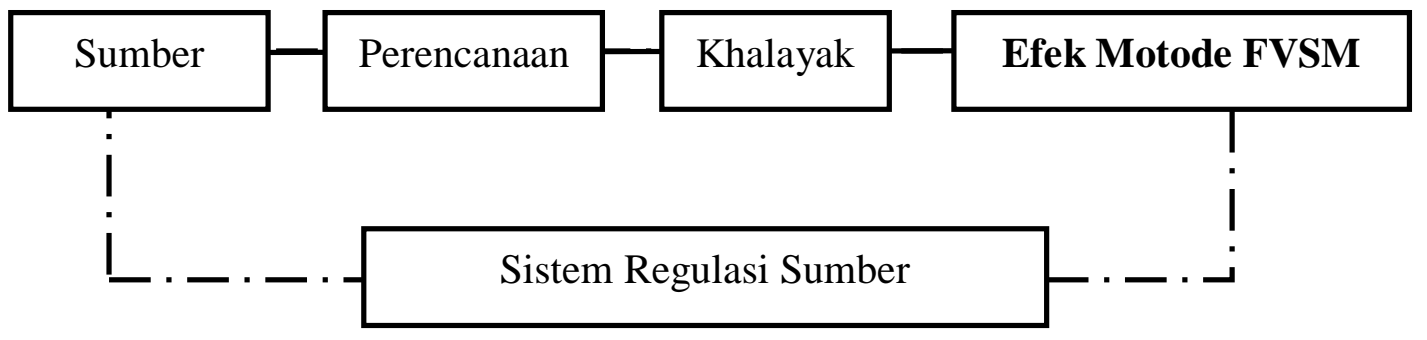

Sumber : Hasil dan Pembahasan Penelitian dengan Olahan Data, 2018

d) Alasan Moral untuk Melindungi Data Pribadi (Moral reasons for Protecting Personal Data) (Wibowo, 2006).

Skema 2. Nilai Keseimbangan Moral Privasi Pemilik Kendaraan Leasing

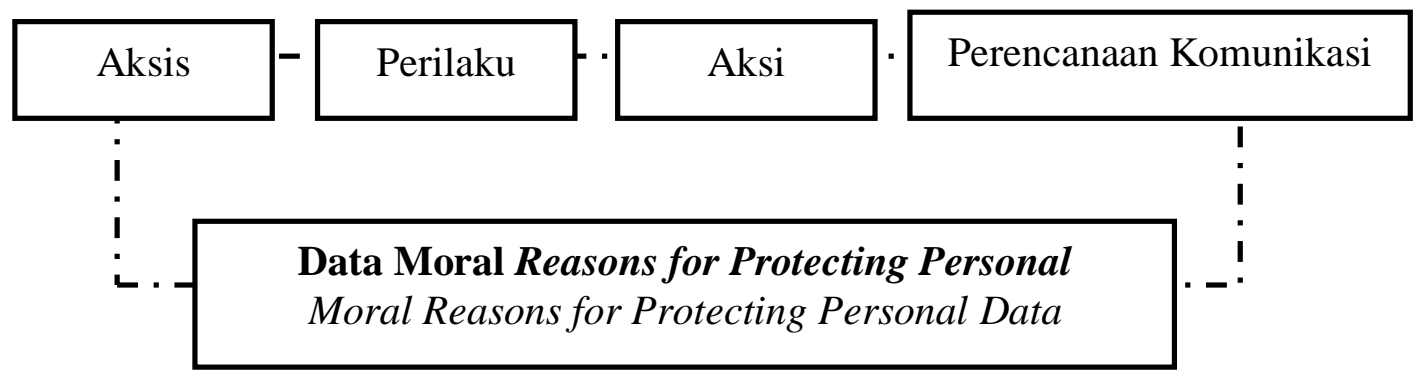

Sumber : Hasil dan Pembahasan Penelitian dengan Olahan Data, 2018

e) Hukum, Regulasi, dan Kontrol Akses tidak Langsung (law, regulation, and indirect control over access).

Dalam hukum jaminan dikenal dua jenis jaminan yaitu jaminan secara umum dan jaminan secara khusus, sedangkan jaminan secara khusus masih dapat dibedakan lagi menjadi jaminan kebendaan dan jaminan orang penanggungan utang (Fatma Paparang et al., 2014). Jaminan secara umum dan penanggungan utang tidak sepenuhnya memberikan kepastian mengenai pelunasan utang, dikarenakan kreditur 
tidak mempunyai hak mendahulu sehingga kedudukan kreditur tetap sebagai kreditur konkuren terhadap kreditur-kreditur lainnya. Jaminan kebendaan yang dikenal dalam hukum yaitu pertama, jaminan dalam bentuk gadai yang diatur dalam Pasal 11501160 KUH Perdata. Gadai, sesuai dengan pengertian yang diberikan dalam KUH Perdata, merupakan jaminan dalam bentuk kebendaan bergerak yang pelaksanaannya dilakukan dengan cara penyerahan kebendaan bergerak (yang digadaikan) tersebut kedalam kekuasaan kreditur. Kedua, adalah hipotek yang diatur dalam Pasal 11621178 KUH Perdata. Dalam hipotek yang menjadi jaminan adalah barang tidak bergerak yang dibuat dengan akta hipotek. Ketiga adalah hak tanggungan sebagaimana diatur dalam UU No. 4 Tahun 1996 yang mengatur mengenai penjaminan atas hak-hak atas tanah tertentu berikut kebendaan yang dianggap melekat dan diperuntukkan untuk dipergunakan secara bersama-sama dengan bidang tanah yang atasnya terdapat hak-hak atas tanah yang dapat dijaminkan dengan hak tanggungan. Keempat adalah jaminan fidusia, yang diatur dalam UU No. 42 Tahun 1999 tentang jaminan fidusia (Mulyani, 2010).

Sebelum dikeluarkan UU No. 42 Tahun 1999, eksistensi fidusia sebagai pranata jaminan diakui berdasarkan yuridisprudensi. Sesuai hasil penelitian dan kajian normatif dari penulis, ternyata sistem penjaminan fidusia masih mengalami kendala seperti: (a) Permasalahan di sekitar dasar kepercayaan : Penyerahan jaminan yang didasarkan pada sistem kepercayaan tersebut disebut sebagai fiduciare eigendom overdracht, (b) Adanya kesengajaan sebagai perbuatan melawan hukum oleh satu pihak : baik pemberi dan penerima jaminan terutama itikad buruk dari penerima jaminan untuk tidak mendaftarkan, maka bagaimana kepastian hukum dalam penyelesaian perkara belum tegas diatur, (c) Terkait dengan Jaminan Perorangan : Penerima Fidusia tidak langsung memiliki objek yang menjadi jaminan fidusia yang diserahkan oleh pemberi fidusia, sehingga jaminan fidusia merupakan suatu teori jaminan. Bagaimana kalau satu pihak beritikad buruk, tentu harus ditegas batasanbatasan pengaturan tentang itikad buruk ada adanya kepastian hukum (Hayatdian, 2013).

\section{2) Analisis Komunikasi (Communication Analysis)}

Pada sistem dengan metode FVSM sebagai sistem fidusia (Yodiansyah, Hefri, 2016), yaitu :

a) Sistem dengan nilai tertentu dalam pikiran (system with a certain value in mind).

b) Dengan pelakuan pada penelitian ini dapat dispesifikan dalam kebutuhan privasi Pendekatan penilaian dampak diusulkan pola keseimbangan kendaraan fiducative. Dengan metode sistem transmisi fidusia pada pihak leasing wajib mendaftarkan setiap transaksi kredit didepan notaris atas perjanjian fedusia ini. Sehingga sistem fidusia pada metode alur sistem fidusia kendaraan dengan metode Fiduciary Vehicle System Methods (FVSM) pada skema sistem komunikasi bisnis dengan sistem fidusia menyelesaian kendaraan sengketa kendaraan, dapat diilustrasikan (Jumaili, 2005) dalam sistem skema berikut ini : 
Skema 3. Fiduciary Vehicle System Methods (FVSM).

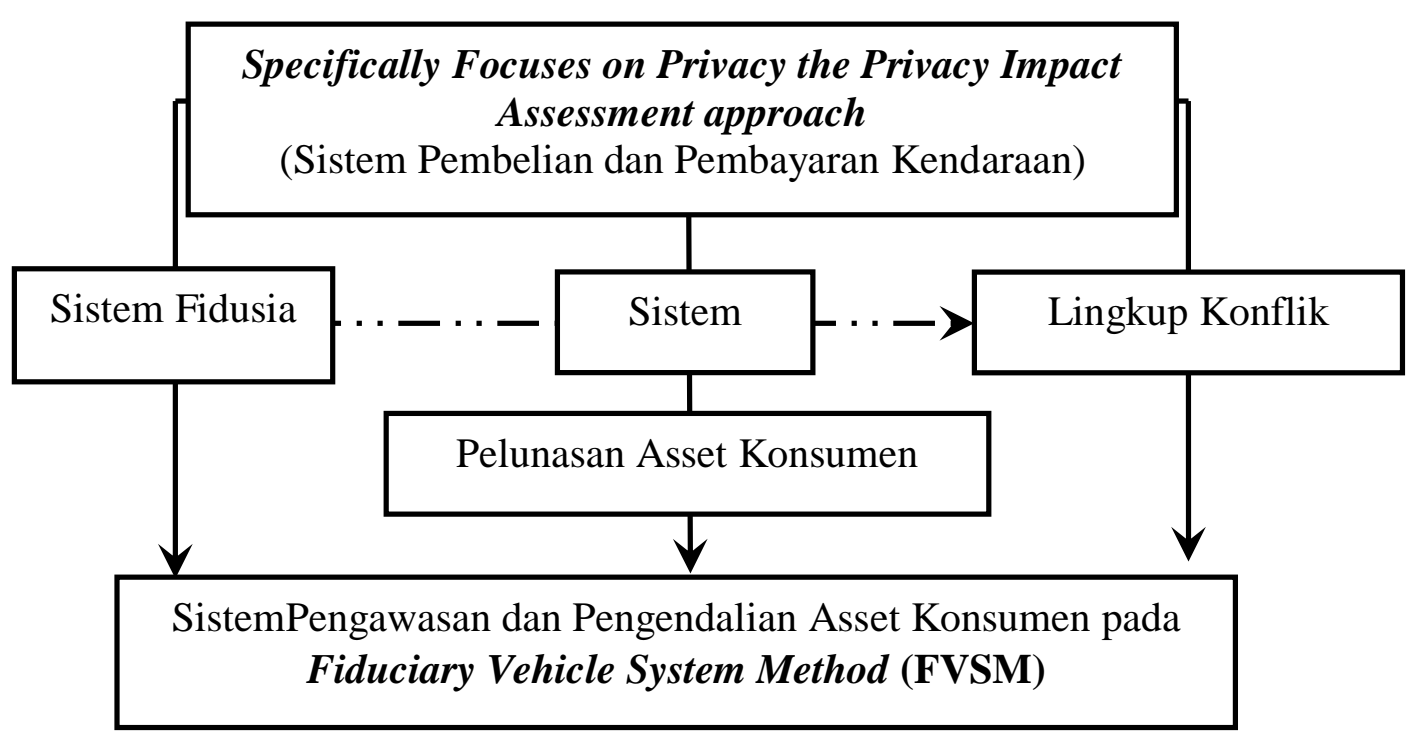

Sumber : Hasil dan Pembahasan Penelitian dengan Olahan Data, 2018.

c) Data Pribadi

Didefinisikan dalam hukum (Sudapet et al., 2018)sebagai data yang dapat dikaitkan dengan orang yang alami. Ada dua cara di mana tautan ini dapat dibuat; mode referensial dan mode non-referensial. Pada data kualifikasi hukum terutama berkaitan dengan 'referensi penggunaan'pada jenis deskripsi data kualifikasi, jenis penggunaan yang dibuat atas dasar hubungan kenalan (mungkin) dari pembicara dengan objek pengetahuan secara privasi (Spiekermann-Hoff, Oetzel, Oetzel, \& Spiekermann, 2017).

Pada masyarakat yang sering menggunakan kualitas bidang kajian sistem Hukum dalam mempelajari fungsi dan tugas pada pola sistem Hukum. Kehidupan masyarakat yang memiliki berbagai keputusan kebutuhan yang memotivasi minat dan keinginan memiliki sebagai syarat kegunaan. Pola masyarakat ini dapat dikatakan sebagai lingkup terapan sistem masyarakat sebagai pola keseimbangan hidup masyarakat. Pada dasarnya sistem digunakan untuk memberikan perlakuan dengan alasan rencana kognitive sosial demi tercapai tujuan tertentu. Pola keseimbangan hidup misalnya yang paling ideal untuk jaminan hidup masyarakat sebagai lingkup terapan dari sistem yang mereka anut dalam mempelajari sistem masyarakat itu.

Istilah sistem dalam pengguna sebagai referensi dalam mempelajari fungsi dan cara masyarakat pada pola keseimbangan hidup masyarakat, misalnya, sistem keseimbangan yang dapat dihindarkan dengan lingkup konflik seperti kendaraan fiducative balances. Dengan sistem sebagai salah satu mekanisme "fiduciary balances system" yang ideal untuk jaminan tentunya kebijakan private pada sistem masyarakat sebagai sistem pembayaran kendaraan fiduciary responsibility dari sistem fidusia yang dapat diakses dengan tujuan metode sistem fidusia itu.

Sistem "fiduciary balances system" adalah pola keseimbangan yang dapat mengundang lingkup konflik leasing kendaraan fiducative dengan problem sistem pembayaran kendaraan fiduciary responsibility yang dapat dihindarkan dengan sistem fidusia. 
Sehingga sistem fidusia dapat dihindar dengan pola kekerasan pada sistem masyarakat yang kompleks itu dengan berbagai keputusan kebutuhan masyarakat.

3) Kebijakan Privasi (Privacy Policy)(Mulyani, 2010).

Sistem "fiduciary balances system" sebagai pola keseimbangan yang dapat mengundang lingkup konflik leasing kendaraan fiducative pada masalah sistem dengan pembayaran kendaraan fiduciary responsibility yang dapat dihindarkan dengan sistem fidusia menghindari pola kekerasan pada sistem masyarakat yang kompleks itu dengan berbagai keputusan kebutuhan masyarakat.

Kebijaksanaan masyarakat pada akses informasi masih memerlukan tindakan aksi sebagai sistem memenuhi persyaratan regulasi sumber pada sistem fidusia dengan sesuai dengan skema pada:

Skema 4. Kebijakan Privasi (Privacy Policy)

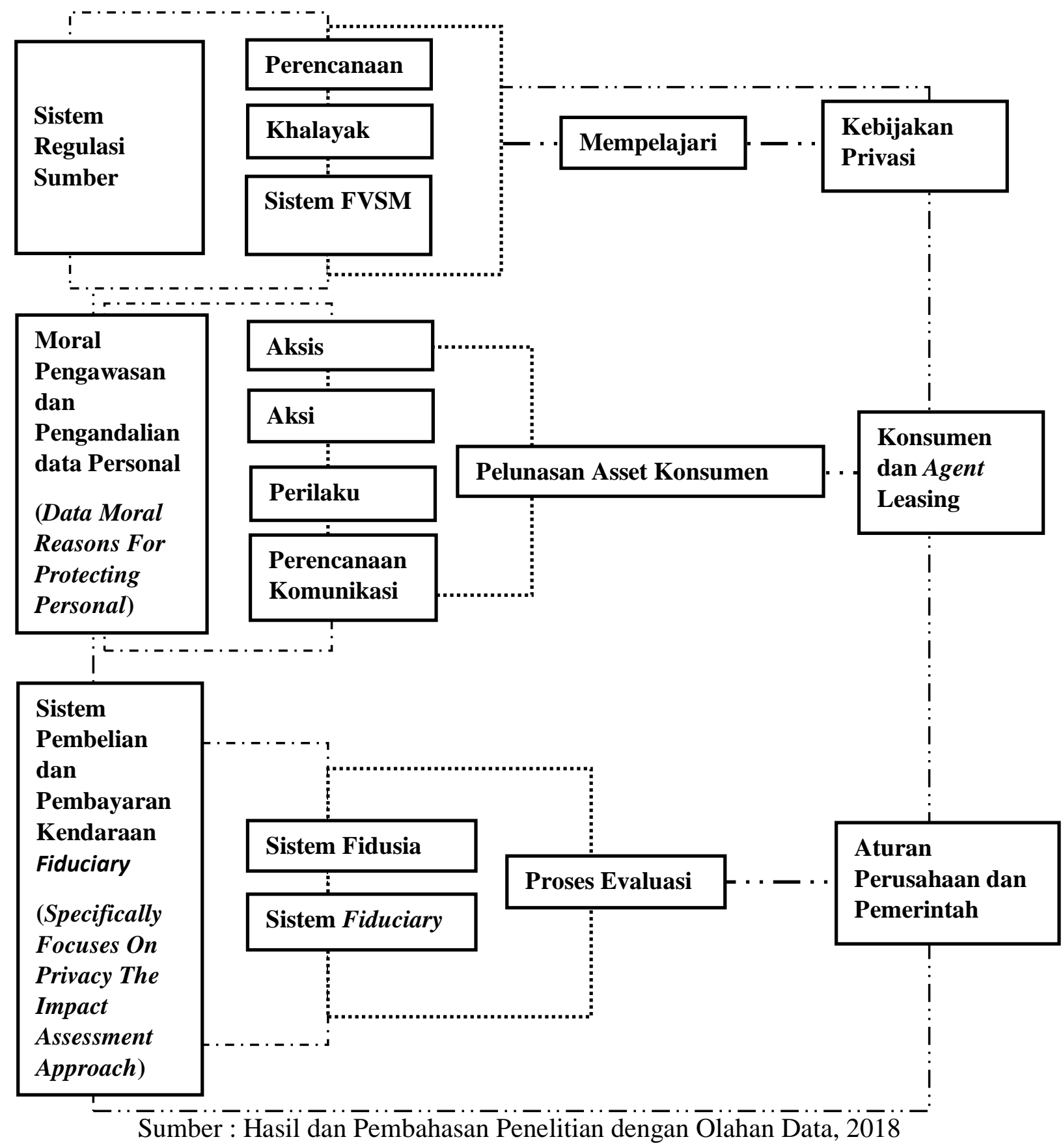


Sistem pembelian dan pembayaran kendaraan (specifically focuses on privacy theimpact assessment approach) dalam proses penyelesaian data perkara yang belum sempat dibayar yang masih mengalihkan sistem fidusia sebagai lingkup terapan sistem regulasi sumber pada pola moral pengawasan dan pengendalian data konsumen sebagai sistem pembelian dan pembayaran kendaraan (specifically focuses on privacy theimpact assessment approach) sesuai dengan aturan sistem keseimbangan yang berlaku.

\section{4) Sistem Kerjasama (Cooperation System)}

Sistem pembelian dan pembayaran kendaraan (specifically focuses on privacy the impact assessment approach) (Fatma Paparang et al., 2014; Hayatdian, 2013; Jumaili, 2005; Mulyani, 2010; Sholihath, 2016; Spiekermann-Hoff et al., 2017; Stem et al., 2005), yaitu :

a) Sistem

Proses sebagai regulasi sumber privasi dengan sistem pembelian dan pembayaran kendaraan.

b) Sistem Fidusia

Sistem kebijakan sebagai sistem keseimbangan pembayaran pada pola pembelian dan pembayaran kendaraan.

c) Lingkup konfliks

Pengawasan dan pengendalian evaluasi kinerja dan perilaku kerja.

d) Proses evaluasi aturan Perusahaan dan Pemerintah

Sistem dan proses peraturan pada sistem pembelian dan pembayaran kendaraan dengan alur konteks pembayaran keseimbangan pada pola pembayaran kendaraan.

\section{5) Sistem Promosi dan Komunikasi (Promotion and Communication System).}

Perhatikan bahwa pendekatan ini seharusnya tidak hanya dilihat sebagai pendekatan audit informasi, tetapi lebih sebagai sarana untuk membuat kesadaran privasi dan kepatuhan sebagai bagian integral dari budaya organisasi dan bukan analisis dengan rekayasa sosial pada audit informasi. Pada manajemen sumber daya manusia (khalayak/konsumen) adalah akun untuk nilai-nilai manusia dalam situasi maupun kondisi komprehensif (Anna, 2015; McQuail, 2013; Pawito, 2007; Thorson \& Wells, 2015; Yodiansyah, 2016).

\section{PENUTUP}

\section{Kesimpulan}

Sistem Fidusia

Sistem Fidusia merupakan proses pengalihan hak kepemilikan sebuah benda dimana hak kepemilikannya masih dalam kekuasaan pemilik benda kendaraan tersebut. Dengan mekanisme leasing kendaraan pada perusahaan dealer dengan istilah Debt. Collector pada metode fidusia sebagai lingkup metode fidusia pada Debt. Collector. Dengan metode Debt. Collector ini dalam perusahaan bisnis pembeli yang mengalami permasalahan yang dengan disidangkan dan pengadilan dengan mengeluarkan surat keputusan untuk menyita kendaraan dan kendaraan dengan dilelang oleh pengadilan dan uang hasil penjualan kendaraan melalui lelang tersebut dengan digunakan untuk melanjutkan membayar utang kredit kepada perusahaan dealer leasing, lalu uang sisanya akan diberikan dengan sistem fidusia ini. Dengan kredit motor menggunakan mekanisme fidusia yang diatur dalam mempermudah dan mengatasi kredit kendaraan pada sebuah perusahaandealer. Maka pihak pemberi kredit akan membeli ke perusahaan dealer dengan mekanisme fidusia ini. Maka, kendaraan tersebut adalah milik pemberi kredit dan hak miliknya dialihkan kepada pembeli. Selama membeli 
yang belum dapat melunasi kredit maka kendaraan tersebut milik pemberi kredit pada perusahaan dealer itu. Sistem fidusia pada alur efektif pengalaman konsumen bisnis, yaitu : (1) Sikap kewajaran pendidikan; (2) Sikap kewajaran pengetahuan; (3) Sikap kewajaran analogy; dan (4) Sikap kewajaran sistem kepercayaan bisnis (Karianga, 2017; Sholihath, 2016; Verabel et al., 2015; Yos, 2009).

\section{Mekanisme Fidusia}

Mekanisme fidusia adalah mekanisme sistem fidusia pada konsumen dengan komunikasi bisnis dengan komunikasi konsumen bisnis, kebijakan konsumen, sistem fidusia, secara sistem kontan maupun sistem kredit, dan Sistem komunikasi bisnis pada sistem pembayaran kendaraan.

\section{Saran}

\section{Kontrak bisnis dan tindakan regulasi fidusia}

Sistem bisnis dan tindakan regulasi fidusia ialah dengan sistem perjanjian fidusia ini melindungi aset konsumen, dan leasing tidak bisa serta merta menarik kendaraan yang gagal bayar karena dengan perjanjian fidusia, alur yg seharusnya terjadi adalah pihak leasing melaporkan ke pengadilan. Proses Fidusia sebagai wacana dengan metode sistem transmisi fidusia pada pihak leasing wajib mendaftarkan setiap transaksi kredit di depan notaris atas perjanjian fedusia ini. Sehingga sistem fidusia pada metode alur sistem fidusia kendaraan dengan Fiduciary Vehicle System Methods (FVSM) pada mekanisme seleksi pola sistem komunikasi bisnis, berikut: (1) Sistem; (2) Lingkup Konflik; (3) Sistem Pembelian dan Pembayaran; (4) Sistem Fidusia; dan (5) Pelunasan Asset Konsumen (Jumaili, 2005).

\section{Methodology}

Sistem fidusia adalah sistem fidusia pada alur efektif pengalaman konsumen bisnis pada Fiduciary Vehicle System Methods (FVSM). Perlakuan mekanisme regulasi fidusia sebagai salah satu sistem FVSM dengan mekanisme sistem fidusia pada konsumen dengan komunikasi bisnis dengan komunikasi konsumen bisnis, kebijakan konsumen, sistem fidusia, secara sistem kontan maupun sistem kredit, dan sistem komunikasi bisnis pada sistem pembayaran kendaraan (Mulyani, 2010).

Kontrak bisnis dan tindakan regulasi fidusia yang di proses fidusia sebagai wacana dengan metode sistem transmisi fidusia pada pihak leasing wajib dengan mendaftarkan setiap transaksi kredit didepan notaris atas perjanjian fedusia ini (Spiekermann-Hoff et al., 2017; Stem et al., 2005; Sudapet et al., 2018; Wibowo, 2006). Sehingga sistem fidusia pada metode alur sistem fidusia kendaraan pada Fiduciary Vehicle System Methods (FVSM) padaskema sistem komunikasi bisnis dengan sistem fidusia menyelesaikan kendaraan sengketa kendaraan, dapat diilustrasikan dalam sistem skema, yaitu : (1) Sistem; (2) Lingkup konflik pembayaran kendaraan; (3) Sistem pembelian dan pembayaran kendaraan fiducative sebagai metode pengendalian kendaraan fiducative untuk jaminan mencegah konflik pada pola keseimbangan kendaraan fiducative; (4) Sistem fidusia; (5) Pelunasan asset konsumen (Hayatdian, 2013).

\section{DAFTAR PUSTAKA}

Anas, I. F. (2018). Titik Kritis Pelunasan Sebelum Jatuh Tempo Pembiayaan Properti; Upaya Mewujudkan Perlindungan Konsumen Sektor Jasa Keuangan Syariah, Vol. 1, No. 1. Jurnal Akuntansi Berkelanjutan Indonesia, 1(1), 24-42.

Anna, N. E. V. (2015). Pengguna Web 2.0 Sebagai Media Promosi Perpustakaan Perguruan Tinggi di Indonesia. Record and Library Jurnal, 1(1), 77-82. 
Fatma Paparang, Fakultas Hukum, \& Manado, U. S. R. (2014). Implementasi Jaminan Fidusia Dalam Pemberian Kredit Di Indonesia. Jurnal LPPM Bidang EkoSosBudKum, 1(2), 56-70.

Hayatdian, H. D. (2013). Kajian Hukum Surat Kuasa Dibawah Tangan Sebagai Dasar Pembuatan Akta Jaminan Fidusia. Jurnal Hukum Unsrat, 1(1), 120-135. Retrieved from http://repo.unsrat.ac.id/373/1/KAJIAN_HUKUM_SURAT_KUASA_DIBAWAH_T ANGAN_SEBAGAI_DASAR_PEMBUATAN_AKTA_JAMINAN_FIDUSIA.pdf

Jumaili, S. (2005). Kepercayaan Terhadap Teknologi Sistem Informasi Baru Dalam Evaluasi Kinerja Individual. Seminar Nasional Akuntansi VIII, (September), 15-16.

Karianga, A. (2017). Analisis Hak Konsumen Terhadap Perusahaan yang Dinyatakan Pailit Oleh Hakim Pengadilan Niaga. Lex Administratum, V(7), 109-115.

Lindrawati, \& Surabaya, D. T. F. E. U. W. M. (2009). Sistem Informasi Akuntansi Berbasis Elektronik Data Prosesing. Sistem Informasi Akuntansi Berbasis Elektronik Data Prosesing, I(1), 27-34.

McQuail, D. (2013). Reflections on Paradigm Change in Communication Theory and Research University of Amsterdam. International Journal of Communication, 7, 216-229.

Mulyani, S. (2010). Rekontruksi Pemikiran Yuridis Integral Dalam Pembaharuan Sistem Hukum Jaminan Fidusia Berpilar Pancasila, ISSN : 0854-2031. Hukum Ekonomi Indonesia, 7(0854), 120-133.

Pawito. (2007). Media Komunitas dan Media Literacy. Article, 4(2), 167-177.

Sholihath, D. F. (2016). Pengaruh Sikap konsumen, Kewajaran Harga, dan Kepercayaan Terhadap Niat Konsumen untuk Berbelanja Online di Surabaya. Jurnal Agri, 1(1), 23-28.

Spiekermann-Hoff, S., Oetzel, M. C., Oetzel, M., \& Spiekermann, S. (2017). A systematic methodology for privacy impact assessments: a design science approach. European Journal of Information Systems (EJIS), 23(2), 128-150. Retrieved from http://epub.wu.ac.at/5495/\%0Ahttp://epub.wu.ac.at/

Stem, C., Margoluis, R., Salafsky, N., \& Brown, M. (2005). Monitoring and evaluation in conservation: a review of trends and appraoches. Conservation Biology, 19(2), 295309. https://doi.org/10.1111/j.1523-1739.2005.00594.x

Sudapet, I. N., Sukoco, A., \& Setiawan, I. (2018). Jurnal Darussalam; Jurnal Pendidikan, Komunikasi dan Pemikiran Hukum Islam Vol. IX, No 1. September 2017. ISSN: 1978-4767, ISSN: 2549-4171. Jurnal Darussalam; Jurnal Pendidikan, Komunikasi Dan Pemikiran Hukum Islam, IX(1), 148-160.

Thorson, K., \& Wells, C. (2015). Curated Flows: A Framework for Mapping Media Exposure in the Digital Age. Article, (c), 1-20. https://doi.org/10.1111/comt.12087

Verabel, P., Penggunaan, M., Dan, I., Akuntansi, S., Terhadap, M., Antara, H., ... Indonesia, P. (2015). Jurnal fairness. In Jurnal Fairness (Vol. 5, pp. 1-138). Bengkulu.

Wibowo, A. (2006). Kajian Tentang Perilaku Pengguna Sistem Informasi dalam Pendekatan TAM. System Information. Retrieved from https://www.researchgate.net/publication/228997997_Kajian_Tentang_Perilaku_Pen gguna_Sistem_Informasi_Dengan_Pendekatan_Technology_Acceptance_Model_TA $\mathrm{M}$

Yodiansyah, Hefri, P. B. R. (2016). Literasi Perencanaan Komunikasi. Jurnal Academia.Edu, O(42), 1-29.

Yodiansyah, H. (2016). Paradigma Teori Perencanaan Komunikasi Paradigma Media Literacy; Plan In The Action. Jurnal Academia.Edu, O-O(42). Retrieved from 
www.academia.edu

Yos, F. D. (2009). Analisis Sistem Informasi Akuntansi Penjualan Tunai Untuk Meningkatkan Pengendalian Intern Pada PT. Gendish Mitra Kinarya. Jurnal Akuntansi, Fakultas Ekonomi Universitas Gunadarma, 1(18), 3-4. Retrieved from http://gunadarma.ac.id/library/articles/graduate/economy/2009/Artikel_21205531.pdf 